Neurosurg Focus 20 (1):E10, 2006

\title{
Genetics of choroid plexus tumors
}

\author{
Ian D. Kamaly-Asl, M.B., Ch.B., F.R.C.S.(SN), NaVID Shams, \\ and Michael D. TaYlor, M.D., Ph.D., F.R.C.S.(C) \\ Greater Manchester Neurosciences Centre, Hope Hospital, Manchester, United Kingdom; and \\ Division of Neurosurgery, The Hospital for Sick Children, Toronto, Ontario, Canada
}

\begin{abstract}
Choroid plexus tumors consist of papillomas and carcinomas. A variety of germline and somatic genetic changes have been demonstrated for each of these subtypes. In this paper, the authors summarize the current knowledge of the genetic bases of these tumors.
\end{abstract}

\author{
KEY WoRdS • choroid plexus carcinoma • choroid plexus papilloma $・$ TP53 gene • \\ hSNF5/INII gene - genetics
}

Choroid plexus tumors are rare tumors of neuroectodermal origin. They represent approximately $0.5 \%$ of all brain tumors, and their annual incidence is 0.3 cases per 1 million population. ${ }^{5,29}$ Associated with the development of these tumors are both germline and somatic abnormalities located at several genetic loci.

\section{The TP53 Gene}

The TP53 gene is located on 17p13.1; this gene expresses the protein product $\mathrm{p} 53$, which influences tumor suppression via a variety of mechanisms including DNA repair, apoptosis, cellular differentiation, and angiogenesis. ${ }^{18} \mathrm{~A}$ mutation of the TP53 gene causes a loss of p53 function as well as prolongation of the half life of the protein. This means that increased immunohistochemical staining for p53 protein can be used as a surrogate marker of gene mutation. ${ }^{14}$

Choroid plexus carcinomas are one of the tumors found in Li-Fraumeni families with TP53 germline mutations. ${ }^{8,10}$, ${ }^{26,27}$ In addition, spontaneous germline and somatic p53 mutations have both been identified in patients with choroid plexus carcinomas. ${ }^{28,32}$ Positive nuclear staining for p53 protein is evident in the majority of choroid plexus carcinomas (10 of 11), whereas it is only seen rarely in choroid plexus papillomas (one of 12). ${ }^{3}$ Mutations of TP53 have not been extensively studied in patients with choroid plexus papillomas; however, germline mutations have been reported. ${ }^{11,16}$

\section{The hSNF5/INI1 Gene}

The $h S N F 5 / I N I 1$ gene is located on 22q11.2 and encodes a member of the SWI/SNF adenosine triphosphate-dependent chromatin-remodeling complex. ${ }^{17}$ Germline mutations of this gene have been described as rhabdoid predisposition syndrome. In families with this mutation, researchers have identified the development of both renal and extrarenal malignant rhabdoid tumors, choroid plexus carcinomas, atypical teratoid rhabdoid tumors, and medulloblastomas. ${ }^{17,23}$ Somatic mutations of the $h S N F 5 / I N I 1$ gene have also been reported in cases of choroid plexus carcinoma. ${ }^{32}$ Authors of several papers offer descriptions of the genotypic and phenotypic overlap between choroid plexus carcinomas and atypical teratoid rhabdoid tumors, ${ }^{4,30}$ however, immunohistochemical studies have shown that, in the majority of cases of choroid plexus carcinomas, hSNF5/INI1 protein expression is preserved. ${ }^{6,7}$ It therefore has been suggested that tumors believed to be choroid plexus carcinomas with $h$ SNF5/INII mutations may actually be atypical teratoid rhabdoid tumors. ${ }^{6}$

There is no evidence of $h S N F 5 / I N I 1$ point mutations in patients with choroid plexus papilloma. ${ }^{11}$

\section{Other Syndromes}

Aicardi syndrome is a rare, $\mathrm{X}$ chromosome-linked dominant condition that is observed in female patients. When it does occur in males with the normal allotment of sex chromosomes, this condition proves lethal during the early gestational period. ${ }^{1}$ Affected female patients have callosal agenesis, infantile seizures, and chorioretinal lacunae. These children have visual impairments and usually display severe developmental delays and problematic seizures. Several authors have reported choroid plexus papillomas in girls with Aicardi syndrome. 1,22,24,25

Hypomelanosis of Ito is a descriptive condition caused by a variety of chromosomal abnormalities and is often associated with other neurological and skeletal abnormalities. In the setting of an X;17(q12;p13) translocation, hypome- 
lanosis of Ito has been associated with the development of choroid plexus papillomas. ${ }^{20,21,31}$

The constitutional 9p duplication is another rare abnormality whose association with choroid plexus hyperplasia and choroid plexus papilloma has been reported. ${ }^{12}$ Extra copies of chromosome arm $9 \mathrm{p}$ have also been found in patients harboring either a sporadic choroid plexus papilloma or carcinoma-a finding that implicates this locus in the formation of both of these tumors. ${ }^{15}$

\section{Chromosomal Imbalances}

Multiple chromosomal imbalances have been described in reports of comparative genomic hybridization of choroid plexus tumors. ${ }^{15}$ Patients with choroid plexus papillomas have frequently displayed the following chromosomal additions and deletions: $+7 \mathrm{q}(65 \%) ;+5 \mathrm{q}(62 \%) ;+7 \mathrm{p}(59 \%)$; $+5 \mathrm{p}(56 \%) ;+9 \mathrm{p}(50 \%) ;+9 \mathrm{q}(41 \%) ;+12 \mathrm{p}$ and $+12 \mathrm{q}$ (38\%); +8q (35\%); -10q (56\%); -10p, and -22q (47\%). Patients with choroid plexus carcinomas have primarily displayed the following additions and deletions: $+12 \mathrm{p}$; $+12 \mathrm{q}$, and $+20 \mathrm{p}(60 \%) ;+1,+4 \mathrm{q}$, and $+20 \mathrm{q}(53 \%) ;+4 \mathrm{p}$ (47\%); $+8 \mathrm{q}$ and $+14 \mathrm{q}(40 \%) ;+7 \mathrm{q},+9 \mathrm{p}$, and $+21(33 \%)$; $-22 \mathrm{q}(73 \%) ;-5 \mathrm{q}(40 \%) ;-5 \mathrm{p}$ and $-18 \mathrm{q}(33 \%)$. Certain imbalances are characteristic of the type of tumor and the age of the patient at presentation; from this we can infer a different genetic basis for these tumor variations. A survival analysis showed a survival advantage in patients with choroid plexus carcinomas in whom there was a gain of $9 p$ and a loss of $10 q(p=0.0186, \log$-rank test). Nevertheless, the population group in this analysis was small (10 patients) and was not controlled for different treatments..$^{15}$

\section{Polyomavirus Infection}

The related ubiquitous polyomaviruses SV40, JC, and BK have been implicated in the development of choroid plexus neoplasms. ${ }^{2,9,10,13}$ Choroid plexus tumors are induced experimentally when the common viral gene product, $\mathrm{T}$ antigen, is transgenically expressed in mice. ${ }^{19}$ The mechanism of action is the binding of the large $\mathrm{T}$ antigen with both $\mathrm{p} 53$ and $\mathrm{pRb}$ tumor suppressor proteins, complexes demonstrated in humans harboring choroid plexus tumors.,33

\section{Conclusions}

A variety of genetic loci are implicated in the development of choroid plexus carcinomas and choroid plexus papillomas. The loci associated with carcinoma generally differ from those associated with papilloma, which leads us to infer a separate genetic basis for these two phenotypically related lesions. Carcinomas, in particular, can be difficult to manage in very young patients, and increased knowledge of the molecular biology of these tumors will hopefully lead to improvements in their treatments and outcomes.

\section{References}

1. Aicardi J: Aicardi syndrome. Brain Dev 27:164-171, 2005

2. Bergsagel DJ, Finegold MJ, Butel JS, et al: DNA sequences similar to those of simian virus 40 in ependymomas and choroid plexus tumors of childhood. N Engl J Med 326:988-993, 1992

3. Carlotti CG Jr, Salhia B, Weitzman S, et al: Evaluation of proliferative index and cell cycle protein expression in choroid plexus tumors in children. Acta Neuropathol (Berl) 103:1-10, 2002

4. Gessi M, Giangaspero F, Pietsch T: Atypical teratoid/rhabdoid tumors and choroid plexus tumors: when genetics "surprise" pathology. Brain Pathol 13:409-414, 2003

5. Gupta N: Choroid plexus tumors in children. Neurosurg Clin N Am 14:621-631, 2003

6. Judkins AR, Burger PC, Hamilton RL, et al: INI1 protein expression distinguishes atypical teratoid/rhabdoid tumor from choroid plexus carcinoma. J Neuropathol Exp Neurol 64: 391-397, 2005

7. Judkins AR, Mauger J, Ht A, et al: Immunohistochemical analysis of hSNF5/INI1 in pediatric CNS neoplasms. Am J Surg Pathol 28:644-650, 2004

8. Krutilkova V, Trkova M, Fleitz J, et al: Identification of five new families strengthens the link between childhood choroid plexus carcinoma and germline TP53 mutations. Eur J Cancer 41:1597-1603, 2005

9. Lednicky JA, Garcea RL, Bergsagel DJ, et al: Natural simian virus 40 strains are present in human choroid plexus and ependymoma tumors. Virology 212:710-717, 1995

10. Malkin D, Chilton-MacNeill S, Meister LA, et al: Tissue-specific expression of SV40 in tumors associated with the Li-Fraumeni syndrome. Oncogene 20:4441-4449, 2001

11. Mueller W, Eum JH, Lass U, et al: No evidence of $h S N F 5 / I N I 1$ point mutations in choroid plexus papilloma. Neuropathol Appl Neurobiol 30:304-307, 2004

12. Norman MG, Harrison KJ, Poskitt KJ, et al: Duplication of 9P and hyperplasia of the choroid plexus: a pathologic, radiologic, and molecular cytogenetics study. Pediatr Pathol Lab Med 15: 109-120, 1995

13. Okamoto H, Mineta T, Ueda S, et al: Detection of JC virus DNA sequences in brain tumors in pediatric patients. J Neurosurg 102:294-298, 2005

14. Pollack IF, Finkelstein SD, Woods J, et al: Expression of p53 and prognosis in children with malignant gliomas. N Engl J Med 346:420-427, 2002

15. Rickert CH, Wiestler OD, Paulus W: Chromosomal imbalances in choroid plexus tumors. Am J Pathol 160:1105-1113, 2002

16. Rutherford J, Chu CE, Duddy PM, et al: Investigations on a clinically and functionally unusual and novel germline p53 mutation. Br J Cancer 86: 1592-1596, 2002

17. Sevenet N, Sheridan E, Amram D, et al: Constitutional mutations of the $h S N F 5 / I N I 1$ gene predispose to a variety of cancers. Am J Hum Genet 65:1342-1348, 1999

18. Sherr CJ: Principles of tumor suppression. Cell 116:235-246, 2004

19. Small JA, Blair DG, Showalter SD, et al: Analysis of a transgenic mouse containing simian virus 40 and v-myc sequences. Mol Cell Biol 5:642-648, 1985

20. Steichen-Gersdorf E, Trawoger R, Duba HC, et al: Hypomelanosis of Ito in a girl with plexus papilloma and translocation (X;17). Hum Genet 90:611-613, 1993

21. Sybert VP, Pagon RA: Hypomelanosis of Ito in a girl with plexus papilloma and translocation (X;17). Hum Genet 93:227, 1994

22. Taggard DA, Menezes AH: Three choroid plexus papillomas in a patient with Aicardi syndrome. A case report. Pediatr Neurosurg 33:219-223, 2000

23. Taylor MD, Gokgoz N, Andrulis IL, et al: Familial posterior fossa brain tumors of infancy secondary to germline mutation of the hSNF5 gene. Am J Hum Genet 66:1403-1406, 2000

24. Trifiletti RR, Incorpora G, Polizzi A, et al: Aicardi syndrome with multiple tumors: a case report with literature review. Brain Dev 17:283-285, 1995

25. Uchiyama CM, Carey CM, Cherny WB, et al: Choroid plexus papilloma and cysts in the Aicardi syndrome: case reports. Pediatr Neurosurg 27:100-104, 1997

26. Varley JM, Evans DG, Birch JM: Li-Fraumeni syndrome-a molecular and clinical review. Br J Cancer 76:1-14, 1997 


\section{Genetics of choroid plexus tumors}

27. Vital A, Bringuier PP, Huang H, et al: Astrocytomas and choroid plexus tumors in two families with identical p53 germline mutations. J Neuropathol Exp Neurol 57:1061-1069, 1998

28. Wang L, Cornford ME: Coincident choroid plexus carcinoma and adrenocortical carcinoma with elevated p53 expression: a case report of an 18-month-old boy with no family history of cancer. Arch Pathol Lab Med 126:70-72, 2002

29. Wolff JE, Sajedi M, Brant R, et al: Choroid plexus tumors. Br J Cancer 87:1086-1091, 2002

30. Wyatt-Ashmead J, Kleinschmidt-DeMasters B, Mierau GW, et al: Choroid plexus carcinomas and rhabdoid tumors: phenotypic and genotypic overlap. Pediatr Dev Pathol 4:545-549, 2001

31. Zajac V, Kirchhoff T, Levy ER, et al: Characterisation of $\mathrm{X} ; 17(\mathrm{q} 12 ; \mathrm{p} 13)$ translocation breakpoints in a female patient with hypomelanosis of Ito and choroid plexus papilloma. Eur J Hum Genet 5:61-68, 1997
32. Zakrzewska M, Wojcik I, Zakrzewski K, et al: Mutational analysis of $h S N F 5 / I N I 1$ and TP53 genes in choroid plexus carcinomas. Cancer Genet Cytogenet 156:179-182, 2005

33. Zhen $\mathrm{HN}$, Zhang $\mathrm{X}, \mathrm{Bu} \mathrm{XY}$, et al: Expression of the simian virus 40 large tumor antigen (Tag) and formation of Tag-p53 and Tag-pRb complexes in human brain tumors. Cancer 86: 2124-2132, 1999

Manuscript received September 15, 2005.

Accepted in final form November 18, 2005.

Address reprint requests to: Ian D. Kamaly-Asl, M.B., Ch.B., F.R.C.S.(SN), Greater Manchester Neurosciences Centre, Hope Hospital, Manchester, M6 8HD, United Kingdom. email: ian.kamaly @ srht.nhs.uk. 